\title{
Pullout Behaviour of Screw and Suction Piles in Clayey Soil
}

\author{
${ }^{* 1}$ Kameshwar Rao Tallapragada, ${ }^{2}$ Anuj Kumar Sharma, ${ }^{3}$ Prabodh D Pachpor \\ 1,2,3 Shri Ramdeobaba College of Engineering and Management, Nagpur \\ Email: raotk@rknec.edu,sharmaak@rknec.edu,pachporpd@rknec.edu
}

Received: 13th November 2019, Accepted: 31st January 2020, Published: 29th February 2020

\begin{abstract}
Screw piles are mostly used in the foundations to provide structural stability against axial compression, uplift tension, overturning moment and lateral forces. Where there are problems in poor foundation material, remote locations with reclaimed and soil deposits, screw piles are more commonly used as structural foundation. Previously the behaviour of multiple anchors in clayey soils at different embedment depth with different pitch has not been studied extensively. In this project an experimental programme on model screw anchors was conducted and studied.

The aim behind to choose laboratory tests is to get an advantage of allowing close control of at least some of the variables encountered in practice. In this way, trends and behaviour patterns observed in the laboratory can be of value in developing an understanding of performance of screw piles at larger scales. In addition, observations made in laboratory testing on different screw piles can be used in conjunction on a same graph.
\end{abstract}

\section{Keywords}

Screw Piles, Uplift Tension, Foundation, Embedment, Lateral Forces.

\section{Introduction}

General

Quite often civil engineering construction is required to be done even in poor sub-soil deposits and reclaimed soil deposits. Such deposits mainly include fine grained soils like soft highly compressible clays, marine deposits along coastal belts and low laying areas, and even loose sandy silts etc. Screw Piles, also known as Screwed, Screw-In, Torque and Helical, Piles, Piers or Anchors consist of a steel centre pipe and one or more steel screw flights welded near the toe of pipe and some intervals along the shaft.

\section{Geotechnical Engineering Problems and Solutions}

A system of structure is visualized to comprise of the super structure, the substructure and the foundation soil. Such a structural unit founded on or in contact with soil mass present two categories of engineering problems.

1. Stability problems.

2. Deformation problems.

The stability of a structure refers to its guarantee against shear failure of foundation soil mass on which loads are ultimately transferred. Furthermore, even under working loads, the superstructure foundation soil system is required to perform satisfactorily with its deflections and deformations within the permissible limits. Analysis and prediction of this deformation response constitute deformation problems. This sub structure part in direct contact with soils media, the most scientific and rational approach to obtain realistic solution to both these geotechnical engineering problems is evaluation and prediction of the soil foundation interaction. It is to be realized that the overall behaviour of structural system is governed by as to how the soil and foundation structural elements interact with each other on the development of stresses and strains in both these components of this system. With the development of modern sophisticated method of analysis and design and with the availability of high speed digital computers any complex problem of soil structure interaction can be tackled with confidence.

The majority of past theoretical and experimental research, however, has focused on predicting anchor behaviour and capacity in sand. In contrast, the study of anchors embedded in clay has attracted only limited attention. Most of the results from studies of anchors in clay either consist of simple analytical solutions or are derived empirically from laboratory model tests. The uplift capacity of anchors is typically expressed in terms of a breakout factor, which is a function of the anchor shape, embedment depth, overburden pressure and the soil properties.

\section{Literature Review}

Balla (1961), Turner (1962), Skopec (1963), Spence (1965), Downs and Chierazi (1966), Langley (1967), Adams and Hayes (1967), Meyerhof and Adams (1968), Ali (1968), Ashbee (1969), and Kupferman (1971), Adams, J.I. and Klym, T.W., (1972) and Meyerhof (1973), Rowe (1978) and Gunn (1980), and Davie and Sutherland (1977), Ranjan and Arora (1980), Rowe and Davis (1982), Das et al. (1985a,1985b,1989), Bobbitt, D.W., and Clemence, S.P., (1987), G.V. Rao and Pandey (1988), Som N (1988), Das and Puri (1989), Sloan et at. 1990, Das et al (1994), Clemence, S.P., Crouch, L.K., and Stephenson, R.W., (1994), Cox, R., (1995), Sloan 
and Kleeman (1995), Carville, C.A. and Walton, R.W., (1994), Merifield et at. (1997), Bradka, T.D., (1997), Yu et at. (1998), Bustamante, M. and Gianeselli, L, (1998), Black, D.R. and Pack, J.S., (2002), Deardorff, D. A., (2006), authors have conducted laboratory research into other aspects of plate anchor behaviour of square, rectangular, circular and strip, horizontal anchors in both cohesion less and cohesive soils. Also they presented a new analytical procedure to predict the breakout load and load displacement relationship for strip, square and circular, horizontal anchors in both cohesion less and cohesive soils. The uplift capacity of anchors is typically expressed in terms of a break-out factor, which is a function of the anchor shape, embedment depth, depth ratio, over burden pressure and soil properties. A number of authors have conducted laboratory research into other aspects of plate anchor behaviour. Parameters studied include the influence of soil suction, layered soil, sloping ground and long term loading.

Subbarao, et al (1988), Singh and Siavoshnina (1988), Mandal and Sah (1992) conducted tests on combined anchored earth and geotextile system Semi Z shaped mild steel anchor and non woven geotextile and geogrids was used in the model tests.

\section{Methodology of Load Transfer Mechanism}

During loading, the load applied to the pile is transferred to the surrounding soil. Thus, the ultimate load carrying capacity of the pile is dependent upon the strength of the soil. Soils derive their strength and ultimately their load capacity from several characteristics like the internal friction angle $\varphi$, the adhesion factor $\alpha$, the effective unit weight of the soil $\left(\gamma^{\prime}\right)$ and the undrained shear strength of the soil SU. Part of the load will be transferred to the soil through the pile shaft (adhesion between shaft and soil) and part will be through the helix (bearing). If there is more than one helix, the last part will be transferred to the soil through the cohesion between the column of soil between the helixes and the surrounding soil. Especially, in clayey soils, when the piles are subjected to uplift, a suction force will also be present (which increases the pile uplift capacity). The Geotechnical Engineer will decide the pile diameter, shaft length, helix diameter as well as helix depth, while the Structural Engineer will design the pile to withstand the design load, the torque required for installation, the helix (or helixes) thickness and the welding size.

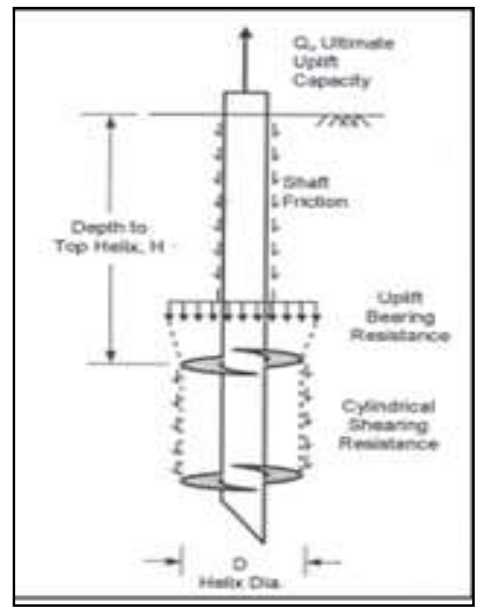

Fig 1: Screw Pile Loading Reactions

\section{Selection of Pile}

Selection of pile depends on the following criteria:

1. Applied loads on Pile: Vertical, Lateral, Moments, Safety Factors and Maximum acceptable movement criteria.

2. Site specific soils information: Soil type, soil description, soil classification, water table level and depth of frost penetration.

3. Pile Geometry: The helix diameter and number of helixes are selected based on the soil parameters and the load the pile is designed to support pile shaft, helix diameter, thickness, number of helixes, embedment depth.

5. Estimation installation torque: The central steel pipe shaft transmits the applied torque during installation and transfers the axial compressive or tensile loads to the helixes during loading.

6. Other factors: Seismic considerations, soil chemistry, etc.

Screw piles, like any other underground steel structure, need special attention paid to corrosion protection. This can be taken into consideration with extra thickness added to the structural required thickness, hot dip galvanization or providing a cathodic protection system; whichever suits the needs and requirements of a specific project. 


\section{Model Preparation} Loading Frame

The testing assembly of screw pile is shown in the Fig 2. It consists of two pulleys with strings, from which one pulley is attached with the loading pan and other one is attached with screw pile shown in Fig 3. Screw pile is inserted in a testing tank filled with soil. Two dial gauges are placed at an appropriate level with respect to the position of piles, for measuring deflections when load is applied in a loading pan.

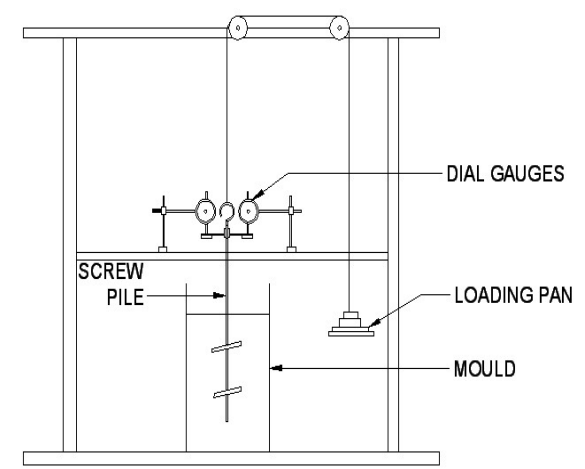

Fig 2: Testing Assembly

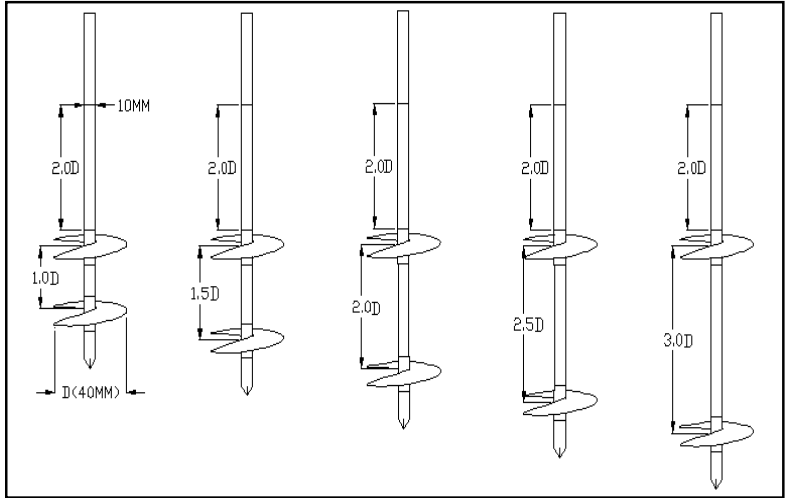

Fig 3: Set of Two Screw Piles

\section{Laboratory Investigations of Soil}

For performing the screw pile test, soil was collected from Seminary hills, Nagpur and laboratory investigation is done. On the basis of laboratory investigation results of soil given in the Table 1, is classified as inorganic silty clay of intermediate plasticity (ML).

\begin{tabular}{|c|l|l|}
\hline Sr. No. & TEST & RESULT \\
\hline 1 & Moisture content & $34 \%$ \\
\hline 2 & Specific Gravity & 2.7 \\
\hline 3 & Plastic Limit & $30.43 \%$ \\
\hline 4 & Liquid Limit & $41.26 \%$ \\
\hline 5 & Permeability & $7.13 \times 10^{-4} \mathrm{~cm} / \mathrm{sec}$ \\
\hline 6 & Free Swell Index & $25 \%$ \\
\hline
\end{tabular}

Table 1: Test Results of Soil Properties

\section{Test Tank Preparation}

Two sets of tanks were used in experimentation. These tanks are made up of cast iron. The dimensions of testing tank are thickness $-5 \mathrm{~mm}$, diameter- $28 \mathrm{~cm}$ and height $-55 \mathrm{~cm}$. The given field soil contains stones, pebbles and vegetation due to which soil becomes truly heterogeneous and anisotropic in nature. The field soil contains moisture, to remove this moisture the field soil is first oven dried at $100^{\circ} \mathrm{C}$ and then sieved by $475 \mu$ sieved which is further tested by various physical characteristics of soil. The oven dried soil is mixed with the water content of $34 \%$ to maintain the field density of the soil. Firstly, water and soil is mixed vigorously till the soil becomes uniform in nature and weighed. The prepared soil is further divided into parts of same weight. The testing tank is filled with soil to the designed depth with each part of soil compacted to $10 \mathrm{~cm}$.

\section{Procedure}

The testing tack is mounted on the assembly position maintaining the centre of the mould with edge of the pile shaft which is attached with the pulley. Then screw pile is inserted into the soil up to the embedment depth. Two dial gauges are placed to measure the deflection at a required position. Weights are added in the loading pan with initial weight of $0.5 \mathrm{Kg} / 1.0 \mathrm{Kg}$ and weights are increased till the shaft comes out of the soil. Deflections to corresponding loads are noted down till the screw pile comes out of the soil. The failure load is then considered regarding with the failure height which is $20 \%$ of the embedment depth. The tests are conducted with one screw pile varying with varying embedment depths, two screws pile with embedment depths of $2 \mathrm{D}$ and $3 \mathrm{D}$ and with varying pitches of $1.5 \mathrm{D}, 2.0 \mathrm{D}, 2.5 \mathrm{D}$ and 3.D. 


\section{Results}

From the Figure 4, Figure 5 and Figure 6, it can be observed that as embedment depth increased the failure load and deflection increased. The failure load for varying embedment and varying pitches with one screw and two screws are given in the Table 2.

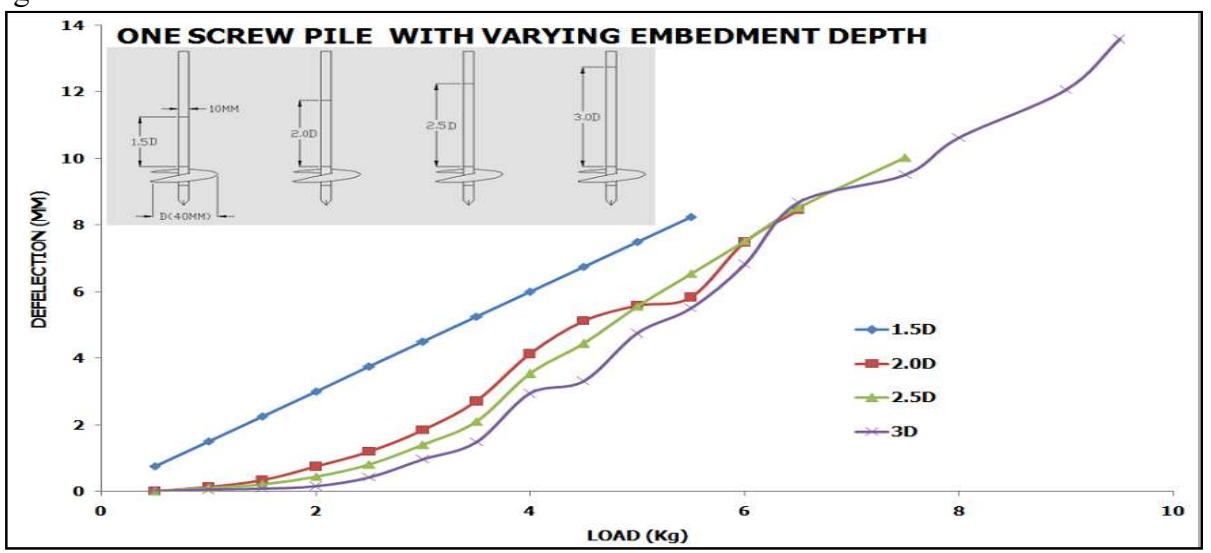

Fig 4: One Screw Pile with Varying Embedment Depth

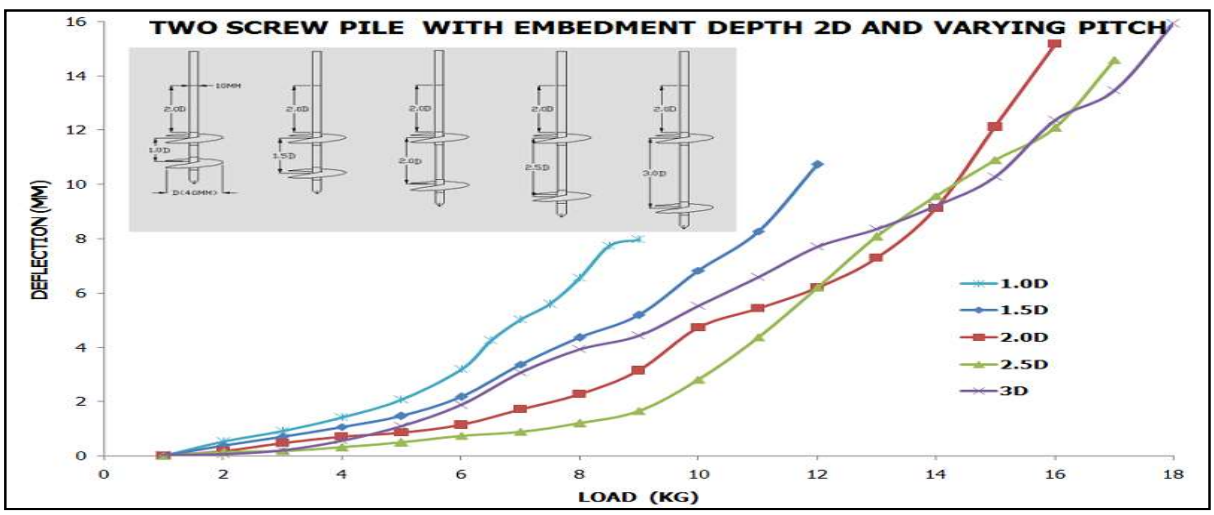

Fig 5: Two Screw Pile with 2D Embedment Depth and Varying Pitch

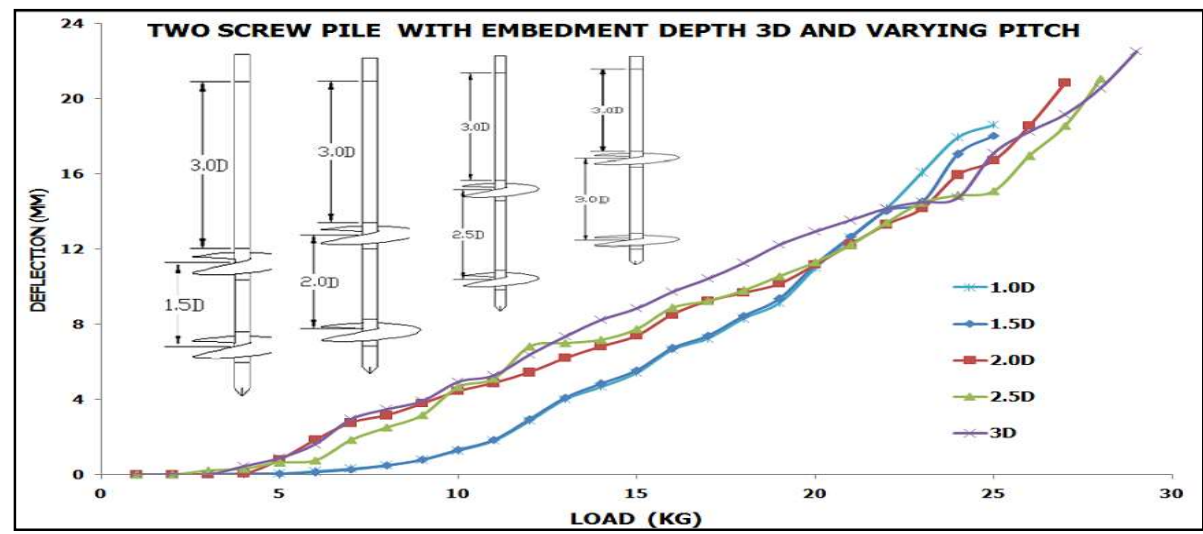

Fig 6: Two Screw Pile with 3D Embedment Depth and Varying Pitch 


\begin{tabular}{|c|c|c|}
\hline Sr. No. & Tests Conducted on various screw piles & Failure Load (Kg) \\
\hline 1. & $\begin{array}{l}\text { With one screw pile : } \\
\text { - } \quad \text { Having Embedment Depth } 1.5 \mathrm{D}(60 \mathrm{~mm}) \\
\text { - } \quad \text { Having Embedment Depth 2D }(80 \mathrm{~mm}) \\
\text { - } \quad \text { Having Embedment Depth 2.5D }(100 \mathrm{~mm}) \\
\text { - } \quad \text { Having Embedment Depth 3D }(120 \mathrm{~mm})\end{array}$ & $\begin{array}{l}5.5 \\
6.5 \\
7.0 \\
9.0\end{array}$ \\
\hline 2. & 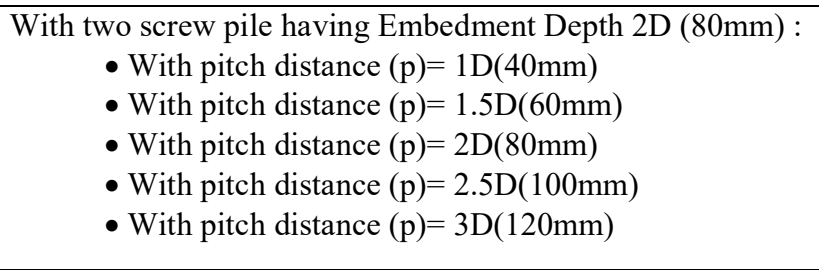 & $\begin{array}{c}9.0 \\
12.0 \\
16.0 \\
17.0 \\
17.5\end{array}$ \\
\hline 3. & $\begin{array}{c}\text { With two screw pile having Embedment Depth 3D }(120 \mathrm{~mm}) \\
\text { - With pitch distance }(\mathrm{p})=1 \mathrm{D}(40 \mathrm{~mm}) \\
\text { - } \quad \text { With pitch distance }(\mathrm{p})=1.5 \mathrm{D}(60 \mathrm{~mm}) \\
\text { - } \quad \text { With pitch distance }(\mathrm{p})=2 \mathrm{D}(80 \mathrm{~mm}) \\
\text { - } \quad \text { With pitch distance }(\mathrm{p})=2.5 \mathrm{D}(100 \mathrm{~mm}) \\
\text { - With pitch distance }(\mathrm{p})=3 \mathrm{D}(120 \mathrm{~mm})\end{array}$ & $\begin{array}{l}25.0 \\
26.0 \\
27.0 \\
28.0 \\
28.5\end{array}$ \\
\hline
\end{tabular}

Table 2: Failure Loads of Various Screw Piles with Varying Depth and Varying Pitches

\section{Conclusion}

1. From the pullout test of screw pile, it is concluded that as the embedment depth increases the load carrying capacity of pile also increased and gets more strength to pile foundation.

2. It is observed that as the number of screws increased in pile, it increases anchor strength of pile and takes more load as compared to single screw pile.

3. It is observed that as the pitch increased between the two screws, the load carrying capacity of pile increases nearly $20 \%$.

\section{References}

1. Adams, J.I. and Klym, T.W., 1972. A Study of Anchors for Transmission Tower Foundations. Canadian Geotechnical Journal, Vol. 9, No. 1, pp. 89-104.

2. Black, D.R. and Pack, J.S., 2002. Design and Performance of Helical Screw Piles in Collapsible and Expansive Soils in Arid Regions of the United States. Proceedings of the 9th International Conference on Piling and Deep Foundations, pp. 469-476.

3. Bobbitt, D.W., and Clemence, S.P., 1987. Helical Anchors: Application and Design Criteria. Proceedings of the 9th Southeast Asian Geotechnical Conference, Vol. 2, pp. 6-105 - 6-120.

4. Bradka, T.D., 1997. Vertical Capacity of Helical Screw Anchor Piles. M.S. Report, Geotechnical Group, Department of Civil Engineering, University of Alberta.

5. Bustamante, M. and Gianeselli, L., 1998. Installation Parameters and Capacity of Screwed Piles. Proceedings of the 3rd International Geotechnical Seminar on Deep Foundations on Bored and Auger Piles: BAP III, pp. 95-108.

6. Carville, C.A. and Walton, R.W., 1994. Design Guidelines for Screw Anchors. Proceedings of the International Conference on Design and Construction of Deep Foundations, Vol. 2, pp. 646-655.

7. Clemence, S.P., Crouch, L.K., and Stephenson, R.W., 1994. Prediction of Uplift Capacity for Helical Anchors in Sand. Proceedings of the 2nd Geotechnical Engineering Conference, Cairo.

8. Deardorff, D. A., 2006. Torque Correlation Factors for Round Shaft Helical Piles. Deep Foundations Institute Symposium on Helical Pile Foundations, Nov., 2007, 20 pp. 